\author{
Military Technical College \\ Kobry El-Kobbah, \\ Cairo, Egypt
}

\section{$5^{\text {th }}$ International Conference \\ on}

Chemical \& Environmental

Engineering

25 - 27 May, 2010.

EM-3

\title{
WARHEAD FRAGMENTS MASS DISTRIBUTION USING NUMERICAL COMBINATION OF MOTT'S AND HELD'S FORMULAS
}

\author{
Mohammed H. M. Abuuznein* and Mohammed A. AAbdalla**
}

\begin{abstract}
Design of the high explosive (HE) warheads is confronted with series of contradictory requirements. Modeling of fragment size, mass distribution is one of the great importance for determination of fragmenting warhead efficiency. In this work a numerical solution for Mott's formula was built using MATLAB for determination of mass distribution and average mass of fragments. A $105 \mathrm{~mm}$ high explosive HE projectile was tested in a pit test and the results are comparing with numerical results. The comparison show small error in average mass of fragments $(0.03 \%)$. A combination of this method with Held's formula leads to calculate the warhead characteristics $\lambda$ and B. This gives a good approach of calculating different fragmentation parameters for different warheads
\end{abstract}

\section{Keywords}

Average mass of fragments, mass distribution, mass of fragment, natural fragmentation, number of fragments. 


\section{INTRODUCTION}

Measurements of warheads performance are expensive. The results are strongly dependent on details of warhead design, necessary economies at the measurement facility, and round-toround variations. Therefore it is essential to have a capability to make warheads performance predictions in the earliest phases of weapon preliminary design.

Natural fragmentized projectiles or warheads result in a wide range of random fragments distribution (masses and geometry). Expansion of the warhead case under detonation products pressure causes splitting of the warhead body into various sized fragments. For cylindrical steel warhead cases, initial elastic-plastic expansion of the case occurs when it is extended from the original volume to about 1.44 times. When the current case volume being risen to about 2.56 to 3.24 times of the initial warhead volume, the detonation products are released through cracks and subsequently an expanding detonation products cloud is developed beyond the fractured warhead case. [1]

The shapes of fragments from a detonated munition may vary considerably. Many will appear flattened, corresponding to the thickness of the swollen case which is stretched by the expansion that follows detonation. Some fragmentation munitions have a light casing wrapped with a notched metal helix of square cross-section to control the size to some extent and, therefore, the distribution of mass among the fragments. In general purpose munitions; the size of fragment is not controlled; consequently, fragments may vary from dust-like particles to relatively large pieces.

Ordnance warheads are generally axisymetric. This reduces performance calculations to two dimensions. Warhead fragmentation is generally one of two types: natural fragmentation or controlled fragmentation. Natural fragmentation yields a random distribution of fragment sizes (masses) that can be described analytically.

\section{MASS OF THE WARHEAD}

The total mass of the warhead $(\mathrm{m})$ is determine by summation of the mass of warhead case $(\mathrm{mb})$, mass of explosive charge (me) .

$$
\mathrm{m}=\mathrm{m}_{\mathrm{b}}+\mathrm{m}_{\mathrm{e}} \quad(\mathrm{kg})
$$

\subsubsection{Warhead Case Mass}

Is the mass of the warhead body (case). It can be estimated by the following equation:

$$
m_{b}=V_{b} \rho_{b}=\pi \rho_{b} \int\left(R^{2}-r^{2}\right) d(R-r)
$$

Where:

$\mathrm{Vb}$ - volume of the warhead case (m3)

$\rho b-$ density of the warhead case material $(\mathrm{kg} / \mathrm{m} 3)$

$\mathrm{R}$ - external radius of the warhead case $(\mathrm{m})$

$r$ - internal radius of the warhead case $(\mathrm{m})$

\subsubsection{Explosive Charge Mass}

The mass of the explosive charge can be estimated by the following equation:

$$
\mathrm{m}_{\mathrm{e}}=\mathrm{V}_{\mathrm{e}} \rho_{\mathrm{e}}=\pi \rho_{\mathrm{e}} \int \mathrm{r}^{2} \mathrm{dr}
$$

Where: 
Ve - volume of the explosive charge (m3)

$\rho e-$ density of the explosive charge $(\mathrm{kg} / \mathrm{m} 3)$

\section{MOTT AND HELD FRAGMENTS MASS DISTRIBUTION LAW}

The developed natural fragmentation model is based on the Mott's theory of break-up of cylindrical "ring-bombs", in which the average length of the resulting circumferential fragments is a function of the radius and velocity of the ring at the moment of break-up, and the mechanical properties of the metal. Following Mott and Linfoot, the "random variations" in fragment sizes are accounted through the following fragment distribution relationship. $[2,3]$

$$
\begin{aligned}
& \mathrm{N}(\mathrm{m})=\frac{M}{2 \mu} \mathrm{e}^{-(\mathrm{m} / \mu)^{1 / 2}} \\
& \mu=\mathrm{b}^{2} \mathrm{t}^{5 / 3} \mathrm{D}_{\mathrm{i}}^{2 / 3}\left[1+\left(\frac{\mathrm{t}}{\mathrm{D}_{\mathrm{i}}}\right)\right]^{2}
\end{aligned}
$$

Where:

$\mathrm{N}(\mathrm{m})$ - number of fragments of mass greater than $\mathrm{m}$

$\mu \quad$ - half average fragment mass

Gurney and Sarmousakis developed another expression for thin walled warheads (less than 0.6 in.)

$$
\begin{gathered}
N(m)=\frac{M}{\mu_{j}} e^{-\left(m / \mu_{j}\right)^{1 / 2}} \\
\mu^{1 / 2}=\frac{2 A t\left(D_{o}-t\right)^{3 / 2}}{D_{i}} \sqrt{1+\frac{1}{2}\left(\frac{C}{M}\right)} \\
\mu_{j}=\frac{\mu}{j !}
\end{gathered}
$$

For $\mathrm{C} / \mathrm{M}<2, \mathrm{j}=2, \mathrm{C} / \mathrm{M}>2, \mathrm{j}=1$, for thick wall $(>0.015 \mathrm{~m}) \mathrm{j}=3$

Where:

$\mathrm{C}$ - explosive mass

$\mathrm{M}$ - meatal mass

Do,Di -outer and inner diameter of the warhead case (m)

$\mathrm{t} \quad$ - warhead case thickness $(\mathrm{m})$

A,b - a function of the explosive and the case material in equation, the Gurney-Sarmousakis equation. As a rough approximation, for a mild steel case, A=338.1/PCJ, with the detonation pressure (PCJ) in kbar.

Held has developed an experimental approach to represent the fragment mass distribution as a function of a number of fragments. The method of analyzing mass distributions by means of Held's formula is explained as follows [3]

$$
M(n)=M\left(1-e^{-B n^{\lambda}}\right)
$$

Where:

$M(n)$ - mass of fragments of number of fragments greater than $n$

$\mathrm{B}, \lambda$ - constants

To determine the values of $B$ and $\lambda$ it is convenient to take a logarithm of equation (9) so that in a logarithmic representation the point of intersection $n=1$, or $\log n=0$, will give constant $B$ directly on the ordinate axis, and exponent $\lambda$ can be determined from the slope of he straight line (Figure 1). That is 


$$
\log \left(\ln \frac{M}{M-M(n)}\right)=\log B+\lambda \cdot \log n
$$

If the correlation coefficient of the relation Figure 1 is greater than 0.99 the result is accepted else, using the constant $\mathrm{B}$ and $\lambda$ as originally determined, one can now calculate an optimum mass $\mathrm{MB}$, that is, a total mass MB that the best fits this set of equations, as [4]

$$
M_{B}=\frac{M(n)}{1-e^{-B n^{\lambda}}}
$$

The constants $\mathrm{BB}$ and $\lambda \mathrm{B}$ are now determined with this new total mass $\mathrm{MB}$ as

$$
M(n)=M_{B}\left(1-e^{-B_{B} n^{n}}\right)
$$

These set of Held's equations calculations are repeated until the correlation coefficient became greater than 0.99 .

\section{NUMERICAL SOLUTION}

The equations from (1) through (8) are generated for cylindrical warhead and they are not applicable for most types of warheads configurations. Numerical solutions were made to use these equations in the warhead that contain different type of geometric shapes like line, circle, tangent etc.

The way to determine warhead geometrical parameters is by using mathematical functions to determine warhead's geometry. Procedure is straightforward that all we need is the drawing of the warhead (105 mm HE projectile is applied for this research) see Figure 2. Body path is divided in several segments. Every segment has different mathematical function. Here we have six different segments on external body path: (Figure 3)

circle

line

line

line

line

sloped line

Internal warhead body path is also divided in several segments; every segment has different mathematical function. Here also we have six different segments on internal body path: (Figure 4)

line

circle

line

sloped line

circle

line

Finally, the mathematical formulations of the functions which describe warhead external and internal body path are made the calculation is jointed together the warhead body path joint is obtained (see Figure 8). There are eight separate segments of warhead body which we will take into account. 
Basis for computation method, for warhead body and explosive charge is warhead with planes perpendicular on symmetry axis. Elements between planes should be cylinder rings (for warhead body) and cylinder (for explosive charge). One must find the warhead parameter that explain in the equations (1) to (8) for every element and add them together so we can obtain parameters of the warhead.

A computer program is built up using MATLAB the language of technical computing to calculate the above warhead parameters. [5,6,7]. Held experimental technique equations (9) to (12) was used to evaluate the characteristics $\lambda$ and B using accumulation number of fragments from Mott's formula.

\section{RESULTS AND DISCUSSIONS}

Tables 1 to 3 show the mass, and mass distribution results for $105 \mathrm{~mm}$ HE projectile, Table 4 it's for experimental test for $105 \mathrm{~mm}$ HE projectile in a pit test to get mass and size of fragments, Figure 5 show a comparison between numerical and experimental results.

The average masses for experimental and predicting technique were 5.2722 and 5.2737 respectivly with small error about $0.03 \%$. The total number of fragments for exprimental and predecting technique were 2188 and 1955 respectivly with error about 10.7 but the different in weight about $10.6 \%$ (total weight of tested projectile fragments is $11.5355 \mathrm{~kg}$ and $10.31 \mathrm{~kg}$ for calculted one) the cause difference related to the numerical solution that just caculate the metal sandwich with explosive and neglect the nose and the base of the projectile and that is not happened in the real case.

Figure 5 show the mass distibution for exprimental, Mott's and Held's formulas, it is clear that Mott's formula distribution start form small rising graduly up to total number of fragments and this is not usually happened with real warheads that increase or decreae from group to another

\section{CONCLUSIONS}

A combination Held's and Mott's formulae gives a good approach of calculating different fragmentation parameters for different Fragmenting warheads. This will safe a lot of time and minimizes the cost of experiments of developing new fragmenting warheads.

\section{References}

[1] Zecevic B., et.al., "Influence of Warhead Case Material on Natural Fragmentation Performances", 15th DAAAM International Symposium, Vienna, Austria, November 2004.

[2] Baker E., Koon N., and Hirlinger J., "A method for Prediction Fragmentation Characteristics of Natural and Preformed Explosive Fragmentation Munitions", Warheads, Energetic and Combat-support Armament Center, Picatinny Arsenal, New Jersey, USA, September 2001.

[3] Richard L., "Conventional Warhead Systems Physics and Engineering Design", American Institute of Aeronautics and Astronautics, Inc, Vol. 179, USA, 1998.

[4] Manfred H., "Fragmentation Warheads", edited by Joseph C., "Tactical Missile Warheads", chapter 8, American Institute of Aeronautics and Astronautics, Inc, Vol. 155 USA, 1993

[5] Palm III J., "Introduction to MATLAB 6 for Engineers", McGraw Hill, New York, 2001. Chapra C., "Applied Numerical Method with MATLAB for Engineers and Scientists", McGraw Hill, New York, 2005.

[6] Kuncicky C., MATLAB Programming, Pearson Prentice Hall, USA, 2004 


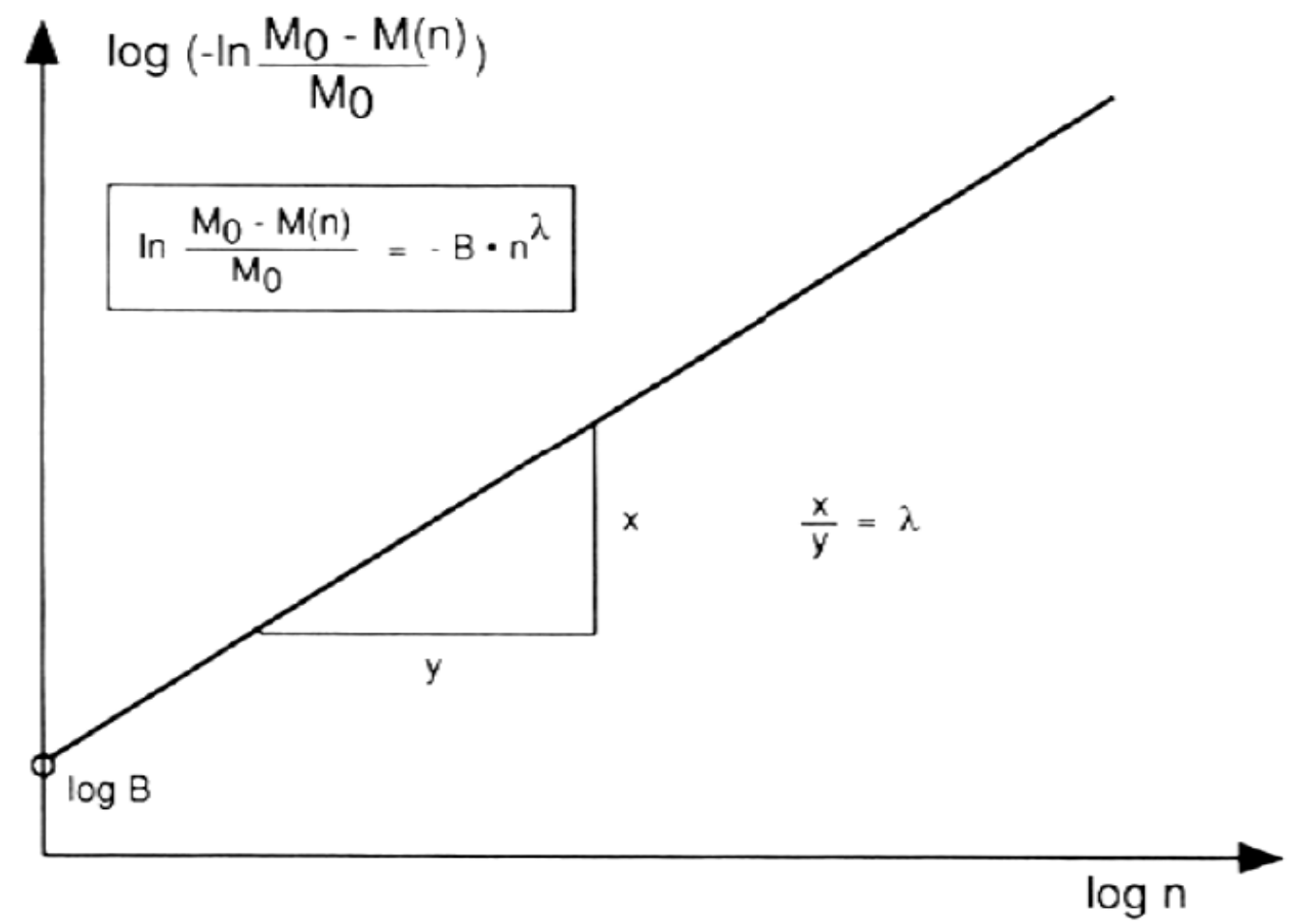

Figure 1: Determination of the constant B and $\lambda$ from the $\log -\log$ plot

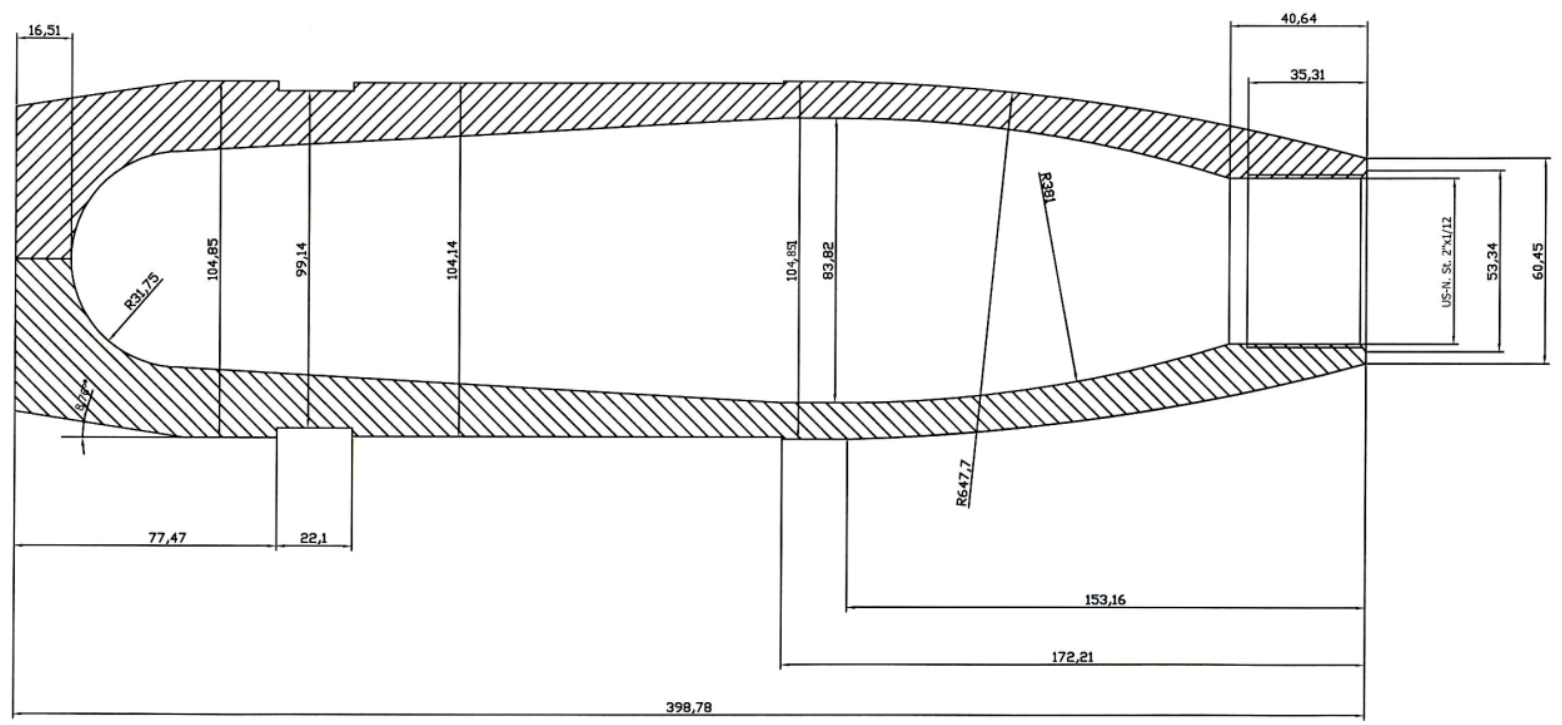

Figure 2: $105 \mathrm{HE}$ projectile drawing 


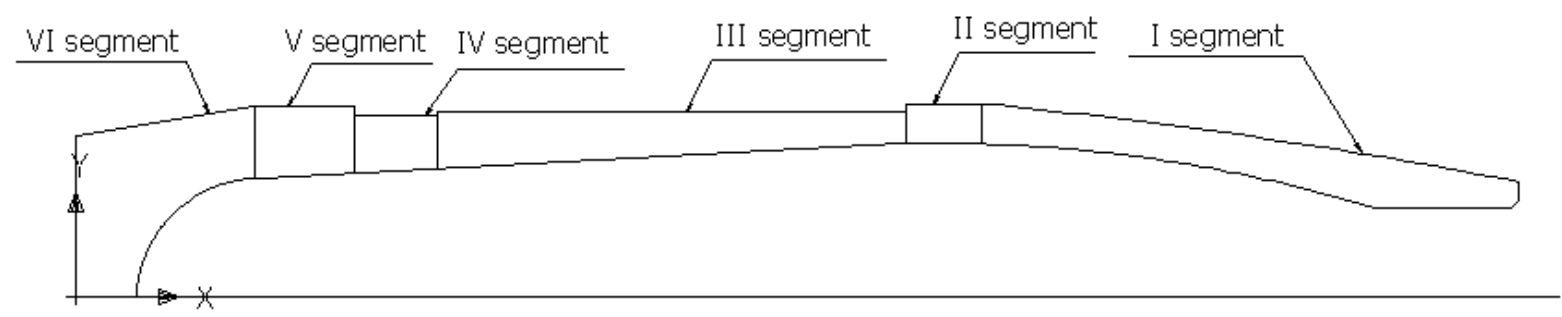

Figure 3: External path of $105 \mathrm{~mm}$ projectile body

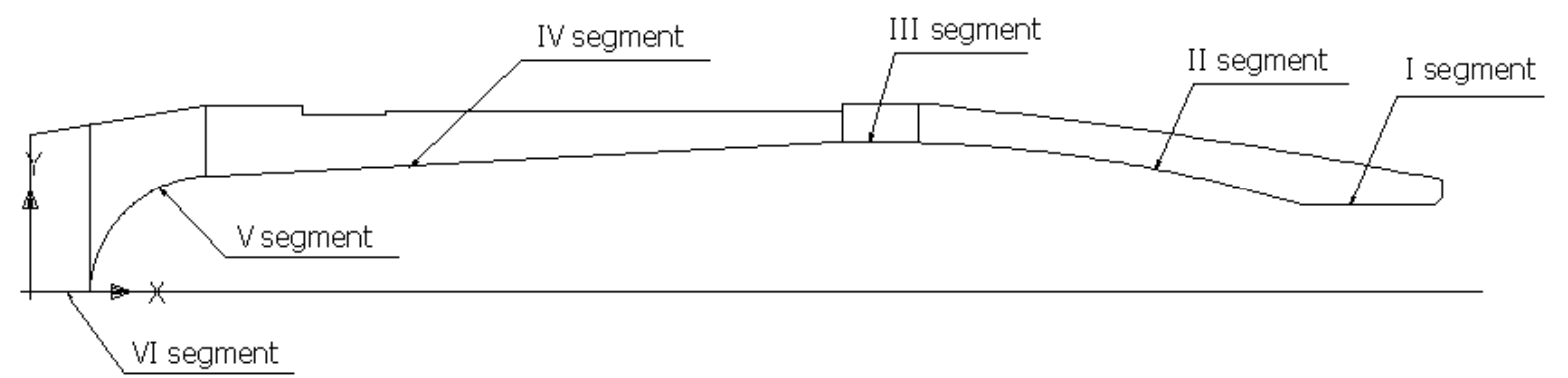

Figure 4: Internal path of $105 \mathrm{~mm}$ projectile body

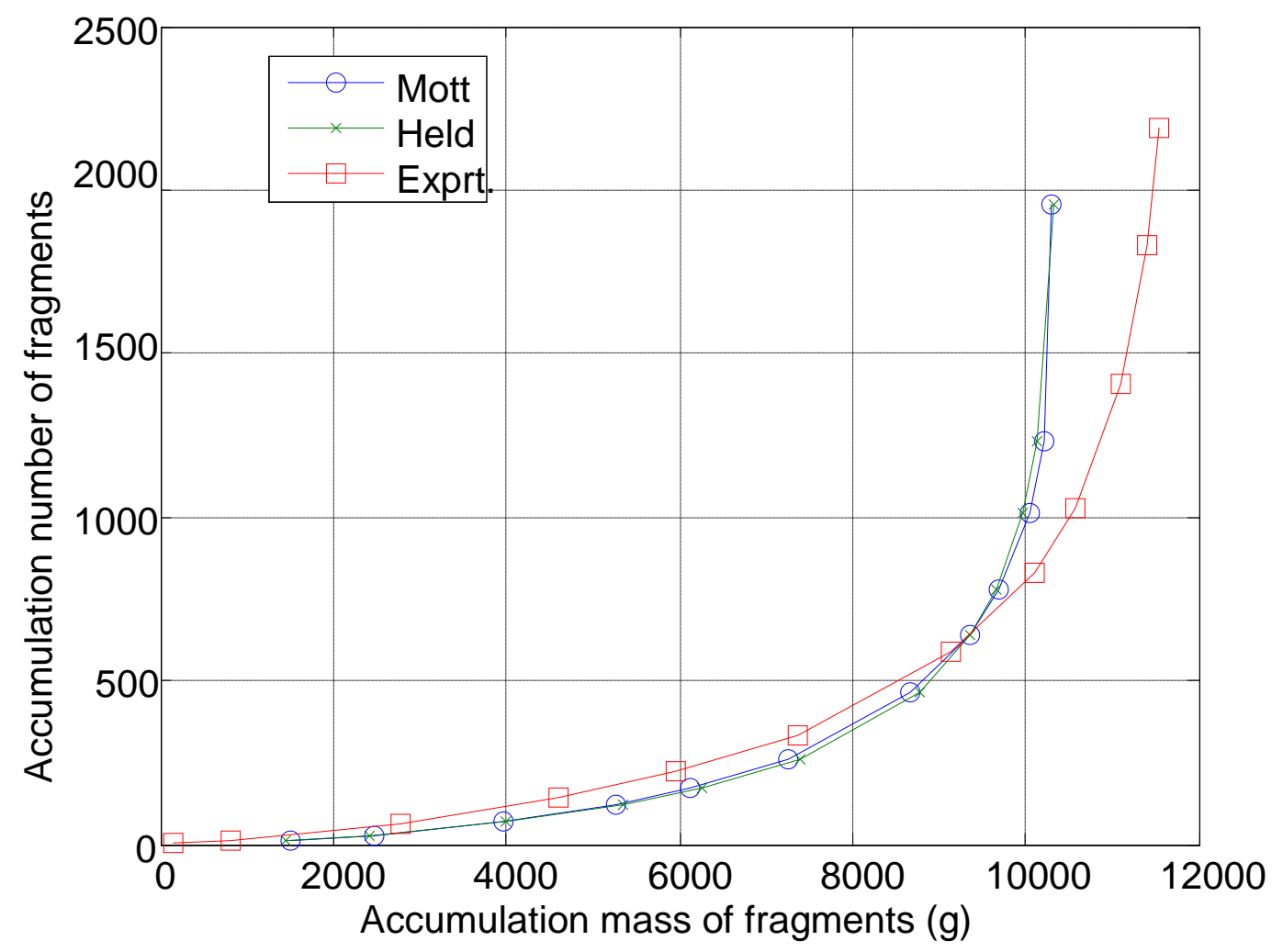

Figure 5: $105 \mathrm{~mm}$ HE projectile mass distribution 
Table 1: $105 \mathrm{~mm}$ HE projectile mass

\begin{tabular}{|c|c|}
\hline Warhead Item & Mass $(\mathrm{Kg})$ \\
\hline Case (steel) & 11.848 \\
\hline Explosive (TNT) & 2.1928 \\
\hline Total Mass & 14.04 \\
\hline C/M & 0.21272 \\
\hline
\end{tabular}

Table 2: mass distribution for $105 \mathrm{~mm}$ HE projectile using Numerical technique

\begin{tabular}{|c|c|c|c|c|c|}
\hline $\begin{array}{l}\text { Mass group } \\
(\mathrm{g})\end{array}$ & $\begin{array}{l}\text { frag. } \\
\text { number }\end{array}$ & $\begin{array}{l}\text { mass of frag. } \\
\text { in group }\end{array}$ & $\begin{array}{l}\text { Cumulative } \\
\text { frag. number }\end{array}$ & $\begin{array}{l}\text { Cumulative } \\
\text { mass of frag. } \\
\text { in group }(\mathrm{g}) \\
\text { Mott's }\end{array}$ & $\begin{array}{c}\text { Cumulative mass } \\
\text { of frag. in group } \\
(\mathrm{g}) \\
\text { Held's }\end{array}$ \\
\hline Up 150 & 3 & 469.81 & 3 & 469.81 & 489.79 \\
\hline $100-150$ & 4 & 515.77 & 7 & 985.58 & 956.23 \\
\hline $75-100$ & 6 & 524.09 & 13 & 1509.7 & 1455.2 \\
\hline $50-75$ & 16 & 965.01 & 29 & 2474.7 & 2419.4 \\
\hline $30-50$ & 39 & 1503.4 & 68 & 3978.1 & 3989.4 \\
\hline $20-30$ & 53 & 1280.1 & 121 & 5258.2 & 5345.9 \\
\hline $15-20$ & 51 & 876.96 & 172 & 6135.1 & 6264.9 \\
\hline $10-15$ & 91 & 1112.1 & 263 & 7247.2 & 7397.1 \\
\hline $5-10$ & 201 & 1431.5 & 464 & 8678.7 & 8766.3 \\
\hline $3-5$ & 173 & 674.22 & 637 & 9352.9 & 9368.6 \\
\hline $2-3$ & 142 & 351.45 & 779 & 9704.4 & 9674.4 \\
\hline $1-2$ & 237 & 344.05 & 1016 & 10048 & 9979.7 \\
\hline $0.5-1$ & 213 & 154.74 & 1229 & 10203 & 10134 \\
\hline $0-0.5$ & 727 & 107.15 & 1955 & 10310 & 10335 \\
\hline
\end{tabular}

Table3: Fragments parameters for $105 \mathrm{~mm} \mathrm{HE}$ using numerical technique

\begin{tabular}{|c|c|}
\hline Average Mass of Fragment $(\mathrm{g})$ & 5.2737 \\
\hline Total Number of Fragments & 1955 \\
\hline$\lambda$ & 0.58137 \\
\hline $\mathrm{B}$ & 0.083032 \\
\hline $\mathrm{R} 2$ (coreleation ceffecient) & 0.99835 \\
\hline
\end{tabular}


Table 4: Mean values for 4 tested $105 \mathrm{~mm}$ HE projectiles in Pit test

\begin{tabular}{|c|c|c|c|c|}
\hline Mass group (g) & frag. number & $\begin{array}{c}\text { mass of } \\
\text { frag. in } \\
\text { group }\end{array}$ & $\begin{array}{c}\text { Cumulative } \\
\text { frag. number }\end{array}$ & $\begin{array}{c}\text { Cumulative } \\
\text { mass of frag. in } \\
\text { group (g) }\end{array}$ \\
\hline $75-100$ & 2 & 162.5 & 2 & 162.5 \\
\hline $50-75$ & 11 & 664.5 & 13 & 827 \\
\hline $30-50$ & 52 & 1941.3 & 65 & 2768.3 \\
\hline $20-30$ & 76 & 1833.3 & 141 & 4601.6 \\
\hline $15-20$ & 79 & 1353.8 & 220 & 5955.4 \\
\hline $10-15$ & 114 & 1400 & 334 & 7355.4 \\
\hline $5-10$ & 254 & 1773.5 & 588 & 9128.9 \\
\hline $3-5$ & 245 & 966.5 & 833 & 10095.4 \\
\hline $2-3$ & 193 & 474 & 1026 & 10569.4 \\
\hline $1-2$ & 379 & 535.3 & 1405 & 11104.7 \\
\hline $0-1$ & 423 & 300 & 1828 & 11404.7 \\
\hline to 0.5 g & 360 & 130.8 & 2188 & 11535.5 \\
\hline Average Mass of Fragment (g) & & 5.2722 \\
\hline
\end{tabular}


